\title{
EXPENSE CHARGES AND BEST ADVICE- OUT OF SIGHT, OUT OF MIND
}

\author{
BY G. V. BUDD
}

(Synopsis of a paper presented to the Society on 16 May, 1989)

THE paper examines the relationship between expense charges and investment performance in the best advice process. In particular the prevailing industry view that expense charges are of relatively peripheral importance is challenged.

With the use of an asset share model the sensitivity of variations in expense charges on final benefits is investigated for specimen personal pensions and endowment contracts. The results are discussed in the context of the industry debate on the Securities and Investment Board's documents on expense and commission disclosure.

A number of important conclusions drawn from the investigations are listed:

-Differences in expense charges between offices are extremely wide.

-Actual expense charges are usually higher than the industry average expenses.

- The differences are usually more significant at terms of 10 years or less than differences in investment performance.

- Over shorter terms it is difficult for an average charging company to overtake the lowest charger unless exceptional investment performance is achieved.

- Early termination values can be extremely penal and should be carefully considered in the best advice process.

- Over longer terms investment performance variations are more significant than variations in expense charges but not overwhelmingly so.

- There is little evidence to suggest that top performing past investment performance is a useful guide to the future.

-Good with profit performance does not automatically equate with superior investment performance as other factors such as expenses, mix of business, miscellaneous surplus and bonus policy are also important.

The closing remarks of the paper are as follows:

Absolute investment performance is always going to dominate other factors in determining the benefits emerging from a particular investment contract. However, within realistic parameters, relative investment performance only becomes the clearly dominant factor over the longer terms where the ability to select the investment winners and losers is more doubtful. For this reason the known initial level of expense charges should become an important factor, alongside the assessment of future investment performance, in the best advice process. 